\title{
Cadmium Exposure Alters Rhizospheric Microbial Community and Transcriptional Expression of Vetiver Grass
}

OPEN ACCESS

Edited by:

Katharina Pawlowski, Stockholm University, Sweden

Reviewed by:

Peter Andeer,

Lawrence Berkeley National Laboratory, United States Aichun Zhao,

Southwest University, China

${ }^{*}$ Correspondence:

Bin Wu

wubin824@sina.com

Specialty section:

This article was submitted to Plant Symbiotic Interactions, a section of the journal

Frontiers in Plant Science

Received: 04 November 2021

Accepted: 31 January 2022

Published: 25 February 2022

Citation:

Wu B, Li J, Peng D, Wang Z and Xu H (2022) Cadmium Exposure Alters Rhizospheric Microbial Community and Transcriptional

Expression of Vetiver Grass.

Front. Plant Sci. 13:808844.

doi: $10.3389 /$ fp/s.2022.808844

\author{
Bin Wu ${ }^{1,2 *}$, Jia $\mathrm{Li}^{1}$, Dinghua Peng ${ }^{3}$, Ziru Wang ${ }^{3}$ and Heng $X u^{3}$ \\ ${ }^{1}$ College of Ecology and Environment, Chengdu University of Technology, Chengdu, China, ${ }^{2}$ State Key Laboratory \\ of Geohazard Prevention and Geoenvironment Protection, Chengdu University of Technology, Chengdu, China, ${ }^{3}$ Key \\ Laboratory of Bio-Resource and Eco-Environment of Ministry of Education, College of Life Sciences, Sichuan University, \\ Chengdu, China
}

Vetiver grass (Chrysopogon zizanioides L.) has been used to remediate cadmium (Cd)-contaminated soil, while there have been few studies on the influence of $\mathrm{Cd}$ exposure on the rhizospheric microbial community and transcriptional expression of $C$. zizanioides. In this study, we investigated the response of the rhizospheric microbial community and transcriptional expression of C. zizanioides in $20 \mathrm{mg} / \mathrm{kg}$ Cd-contaminated soil. The results showed that Cd levels in the roots and shoots of C. zizanioides reached 250.80 and $73.40 \mathrm{mg} / \mathrm{kg}$, respectively. The Cd exposure changed the rhizospheric bacterial community, resulting in the significant enrichment of Sphingomonas, Lysobacter, and Gemmatimonadetes in Cd-contaminated soil. In addition, 880 and 3,419 differentially expressed genes were identified in the plant roots and shoots, respectively, in response to Cd stress. Among these, the overexpressed genes associated with redox homeostasis, glutathione (GSH) metabolism, cell wall biosynthesis, and transmembrane transport pathways were found to participate in Cd detoxification in C. zizanioides. These findings could be useful for understanding the selective variation of the rhizospheric microbial community and the detoxification mechanisms of $C$. zizanioides in Cd phytoremediation.

Keywords: vetiver grass, microbial community, whole transcriptome, cadmium, soil

\section{INTRODUCTION}

Long-term mining activity is one of the major sources of heavy metal contamination of soils (Zhou et al., 2018). Cadmium (Cd) is one of the most concerning elements in soil because it is highly toxic to plants and humans (O'Connor et al., 2018; Zhang Y. et al., 2021). Although Cd is a nonessential element for plants, it can enter plant tissues via the transporters of essential elements (e.g., calcium, zinc, and iron) and disturb plant growth by affecting the photosynthetic apparatus, carbohydrate metabolism, and nitrate absorption (Khan et al., 2017). The major concern regarding Cd pollution is the high risk of cancer, including lung, bladder, renal, prostate, and breast cancer, as it can affect cell proliferation, differentiation, DNA replication, and protein synthesis (Imseng et al., 2018). Therefore, there is a strong need for the development of low-cost remediation strategies for Cd-contaminated soil (Liu et al., 2018). 
Phytoremediation has been widely examined as an effective, environment-friendly, and low-cost technology for the remediation of mine-contaminated soil (Sarwar et al., 2017). Plants can absorb heavy metals from the surrounding soil through their root system (Cui et al., 2020). Vetiver grass (Chrysopogon zizanioides L.) is a common herb that can effectively immobilize Cd. It has the advantages of being tall, fast-growing, and easily cultivable and has a vast root system (1-2 m) (Wu et al., 2020). Aibibu et al. (2010) found that Cd absorption by the roots of C. zizanioides can reach $2,200 \mathrm{mg} / \mathrm{kg}$ at a concentration of $30 \mathrm{mg} / \mathrm{L} \mathrm{Cd}$ in water. Our previous study also found that $C$. zizanioides could effectively absorb $\mathrm{Cd}$ in soil (Wu et al., 2020). In addition, C. zizanioides can be grown in saline, lime, peat, low fertile soil conditions, and even in extreme temperatures (Attinti et al., 2017). Hence, vetiver grass has great potential for use in the bioremediation of Cd-contaminated soil.

The Cd toxicity is unfavorable for biological growth. In the soil-plant system, rhizospheric microorganisms and plants are the two main biological species. The rhizosphere is an important plant habitat, where metabolism, energy exchange, and signal transduction are much higher than that in other regions (Hu et al., 2018). The microbial community and diversity are closely related to soil contamination, especially by heavy metals (Ruvindy et al., 2016). Previous studies have found that excess concentrations of $\mathrm{Cd}$ can affect soil microbial diversity and might screen out some metal-tolerant bacterial species (e.g., Pseudomonas, Acinetobacter, and Serratia) (Jiang et al., 2019; Liu et al., 2020). Soil microorganisms are important participants in Cd mobility and plant detoxification (Sharma, 2021). Hence, it is important to investigate the changes in the rhizospheric microbial community under Cd stress. The excellent Cd tolerance of $C$. zizanioides is the basis of phytoremediation. In a previous study, we investigated the morphological and physiological characteristics of $C$. zizanioides in the presence of different $\mathrm{Cd}$ levels (Wu et al., 2020). However, the potential mechanisms, especially the molecular mechanisms, underlying the response of C. zizanioides to Cd stress, are still unknown. With the development of next-generation sequencing (NGS) technologies, whole transcriptome sequencing provides comprehensive gene expression profiles that can reveal the molecular mechanisms underlying the response of organisms to biotic and abiotic stresses (Hemme et al., 2010). Recently, changes in the whole transcriptomes of many species (e.g., Hibiscus cannabinus L., Solanum lycopersicum L., and Sedum alfredii) in response to Cd stress have been deeply investigated, revealing key insights into the Cd-tolerant strategies (Chen et al., 2020; Zhang et al., 2020). Cd detoxification pathways in plants were significantly different among different cultivars. For example, Pak Choi transcriptome analysis indicated that the differentially expressed genes (DEGs) in response to $\mathrm{Cd}$ stress were mainly involved in cell wall biosynthesis, glutathione (GSH) metabolism, and abscisic acid signal transduction pathways (Zhou et al., 2016). The DEGs in S. lycopersicum L. under Cd stress were mainly involved in plant hormone signal transduction, antioxidant enzymes, cell wall biosynthesis, and metal transportation ( $\mathrm{Su}$ et al., 2021). However, the detoxification mechanisms of C. zizanioides under Cd stress are still unknown.
The main objectives of this study were to (1) investigate the growth response and $\mathrm{Cd}$ immobilization of vetiver grass in heavily Cd-contaminated soil; (2) reveal the changes of the rhizospheric microbial community under Cd stress; and (3) identify DEGs and elucidate the detoxification mechanisms used by vetiver grass in response to Cd stress.

\section{MATERIALS AND METHODS}

\section{Soil Preparation}

Clean soil was collected from a farmland in Chengdu Plain, China. The soil was air-dried and passed through a 2-mm sieve. The physicochemical properties of the soil were as follows: $\mathrm{pH} 6.9$, organic matter $42.46 \mathrm{~g} / \mathrm{kg}$, total $\mathrm{N} 2.68 \mathrm{~g} / \mathrm{kg}$, total P $0.78 \mathrm{~g} / \mathrm{kg}$, total $\mathrm{K} 16.97 \mathrm{~g} / \mathrm{kg}$, cation exchange capacity 19.70 $\mathrm{cmol} / \mathrm{kg}$, total $\mathrm{Cd} 0.6 \mathrm{mg} / \mathrm{kg}$, total $\mathrm{Cu} 27.35 \mathrm{mg} / \mathrm{kg}$, total $\mathrm{Ni} 18.34 \mathrm{mg} / \mathrm{kg}$, and total $\mathrm{Zn} 33.18 \mathrm{mg} / \mathrm{kg}$. Our previous study indicated that the morphological and physiological characteristics of $C$. zizanioides were significantly altered under the stress of $20 \mathrm{mg} / \mathrm{kg} \mathrm{Cd}$ (Wu et al., 2020). In addition, Cd concentrations over $20 \mathrm{mg} / \mathrm{kg}$ were universally found in the abandoned mining areas in China, including Dexing $\mathrm{Cu}$, Yangjiazhangzhi Mo-Cu, Hongqiling Ni, and Baiyin polymetallic ore deposits (Zhou et al., 2018). Hence, the test soil sample was carefully mixed with the quantitative $\mathrm{CdCl}_{2}$ solution, and the $\mathrm{Cd}$ concentration in the soil was set to $20 \mathrm{mg} / \mathrm{kg}$. Subsequently, the soil samples were packaged into pots (height $13 \mathrm{~cm}$ and diameter $18 \mathrm{~cm}$ ) at $2 \mathrm{~kg} /$ pot and longaged for 8 months.

\section{Pot Experiment}

A pot experiment was conducted in a greenhouse at Sichuan University. Before cultivation, C. zizanioides seeds (Pengyuan Seed Industry Co., Ltd., Guangdong, China) were cultured for 3 days for germination in darkness. Then, twenty healthy and uniform C. zizanioides sprouts were cultivated in clean soil $(-\mathrm{Cd})$ and $\mathrm{Cd}$-contaminated soil $(+\mathrm{Cd})$ in three replicates. During cultivation, the growth conditions were maintained at $14 / 10 \mathrm{~h}$ for day/night duration and $60 \%$ soil field water holding capacity. After 60 days of cultivation, the rhizosphere soil and fresh C. zizanioides were carefully collected. The rhizosphere soil, which is free of roots, was gently shaken off from $C$. zizanioides roots, frozen with liquid nitrogen, and stored at $-80^{\circ} \mathrm{C}$ for microbiome analysis. Meanwhile, fresh C. zizanioides was chipped, frozen, and stored at $-80^{\circ} \mathrm{C}$ for transcriptome analysis.

\section{Analysis of Cadmium Levels in Chrysopogon zizanioides}

The plant roots and shoots were dried at $60^{\circ} \mathrm{C}$ and then ground into power. Plant samples $(0.1 \mathrm{~g})$ were digested by microwave digestion with $5: 4: 3(\mathrm{v} / \mathrm{v})$ of $\mathrm{HNO}_{3}: \mathrm{HClO}_{4}: \mathrm{HF}$, and the $\mathrm{Cd}$ content was measured by atomic absorption spectroscopy (AAS; VARIAN, SpecterAA-220Fs). 


\section{Analysis of Rhizosphere Microbiome}

The genomic DNA of rhizosphere microbes was extracted using the E.Z.N.A. ${ }^{\circledR}$ Soil DNA Kit (Omega Bio-Tek, Norcross, United States), according to the instructions of the manufacturer. The DNA extract was run on $1 \%$ agarose gel, and DNA concentration and purity were determined with NanoDrop 2000 UV-Vis spectrophotometer (Thermo Scientific, Wilmington, United States). The quality of DNA extract is shown in Supplementary Table 1 . The 16S rRNA gene was amplified with primer pairs $338 \mathrm{~F}$ ( $5^{\prime}$-ACTCCTACGGGAGGCAGCAG-3') and 806R (5'-GGACTACHVGGGTWTCTAAT- $\left.3^{\prime}\right)$ and purified using the AxyPrep DNA Gel Extraction Kit (Axygen Biosciences, Union City, CA, United States). Purified amplicons were pooled in equimolar amounts and paired-end sequenced $(2 \times 300)$ on an Illumina MiSeq platform (Illumina, San Diego, United States) by Majorbio Bio-Pharm Technology Co., Ltd. (Shanghai, China). The raw 16S rRNA gene sequencing reads were demultiplexed, quality-filtered by fastp version 0.20.0, and merged using FLASH version 1.2.7 (Chen et al., 2018). Operational taxonomic units (OTUs) with 97\% similarity cutoff were clustered using UPARSE version 7.1, and chimeric sequences were identified and removed (Edgar, 2013). The taxonomy of each OTU representative sequence was analyzed using RDP Classifier version 2.2 against the 16S rRNA database (Silva v138), using a confidence threshold of 0.7. The Student's $t$-test was carried out to test the normal distribution of the data. When data did not meet the normal distribution criteria, they were transformed using Box-Cox or Johnson's function and were analyzed using a nonparametric rank-sum test (Kang et al., 2021). The non-metric multidimensional scaling (NMDS) using a weighted UniFrac distance matrix was carried out using $\mathrm{R}$ software (Kang et al., 2021). The linear discriminant analysis coupled with effect size analysis (LEfSe) was employed to explore statistically different biomarkers between the treated groups (Zhang X. et al., 2021).

\section{Analysis of the Plant Transcriptome}

Total RNA was extracted from plant roots and shoots using TRIzol $^{\circledR}$ Reagent (Invitrogen, Carlsbad, CA, United States), and DNA was removed using DNase I (TaKaRa). Then, the total RNA content was determined by 2100 Bioanalyzer (Agilent Technologies, Santa Clara CA, United States). Subsequently, RNA purification, reverse transcription, library construction, and sequencing were performed at Shanghai Majorbio Bio-Pharm Biotechnology Co., Ltd. (Shanghai, China). The raw data were submitted to the NCBI SRA ${ }^{1}$ with ID number PRJNA772523. To validate the expression data obtained from RNA sequencing (RNA-Seq), eight genes with different expression levels were randomly selected and analyzed by quantitative PCR (qPCR). The primer sequences used in this study are listed in Supplementary Table 2. Three replicates were performed for three separate RNA extracts from three samples, and the results were calculated using $2^{-\Delta \Delta \mathrm{CT}}$.

The raw reads were trimmed and quality controlled, and the clean data thus obtained were used for de novo assembly with Trinity (Grabherr et al., 2011). All transcripts were

${ }^{1}$ http://www.ncbi.nlm.nih.gov/sra searched against NR, String, and Kyoto Encyclopedia of Genes and Genomes (KEGG) databases using BLASTX (cutoff $E$-values $\left.<1.0 \times 10^{-5}\right)$. BLAST2 Gene Ontology (GO) program was used to obtain GO annotations (Conesa et al., 2005). Meanwhile, the metabolic pathway analysis was performed using the KEGG (Ogata et al., 1999). To identify DEGs between $\mathrm{Cd}$ and $+\mathrm{Cd}$ samples, the expression level of each transcript was calculated using the fragments per kilobase of exon per million mapped reads (FRKM) method. RNA-seq by expectationmaximization (RSEM) ${ }^{2}$ was used to quantify gene and isoform abundances (Li and Dewey, 2011). R statistical package software was used for differential expression analysis (Robinson et al., 2010). Furthermore, gene ontology (GO) and KEGG were used to identify DEGs that were significantly enriched in GO terms and metabolic pathways (corrected $p$-value $\leq 0.05$, compared with control).

\section{Statistical Analysis}

Data are presented as mean \pm SD from three replicates. Statistical significance was analyzed using SPSS 18.0 package, and mean values were considered to be different when $p<0.05$ using the least significant difference (LSD). All statistical analyses were performed using Origin 2020 (United States). The bioaccumulation factor (BCF) of $\mathrm{Cd}$ in plants was calculated using the following formula:

$$
\mathrm{BCF}=\frac{\mathrm{Cd} \text { accumulation content in plant }}{\mathrm{Cd} \text { content in soil }}
$$

\section{RESULTS AND DISCUSSION}

\section{Biomass and Cadmium Content of Chrysopogon zizanioides}

The growth and $\mathrm{Cd}$ content of C. zizanioides are presented in Figure 1. It was observed that $\mathrm{Cd}$ exposure significantly inhibited the growth of C. zizanioides. In the $+\mathrm{Cd}$ group, the biomass of root and shoot decreased from 13.66 and $2.09 \mathrm{mg} / \mathrm{kg}$ to 5.11 and $0.85 \mathrm{mg} / \mathrm{kg}$, respectively. Although accumulators possess metal tolerance, their growth can be inhibited when the levels of heavy metals exceed their tolerance limit (Gao et al., 2010). In this study, the soil was heavily contaminated with $20 \mathrm{mg} / \mathrm{kg}$ Cd concentration, which was chosen to cause obviously adverse effects on plant growth (Wu et al., 2019). In contrast, the $\mathrm{Cd}$ concentrations in plant roots and shoots reached 250.80 and $73.45 \mathrm{mg} / \mathrm{kg}$, respectively. The BCF values in plant roots and shoots also reached 12.54 and 3.67, respectively. Moreover, $\mathrm{Cd}$ accumulation in C. zizanioides tissues was significantly higher than other accumulators (Supplementary Table 3), which indicated that C. zizanioides had excellent potential for $\mathrm{Cd}$ phytoremediation, thus decreasing $\mathrm{Cd}$ mobility and bioavailability.

\footnotetext{
${ }^{2} \mathrm{http} / / /$ deweylab.biostat.wisc.edu/rsem/
} 

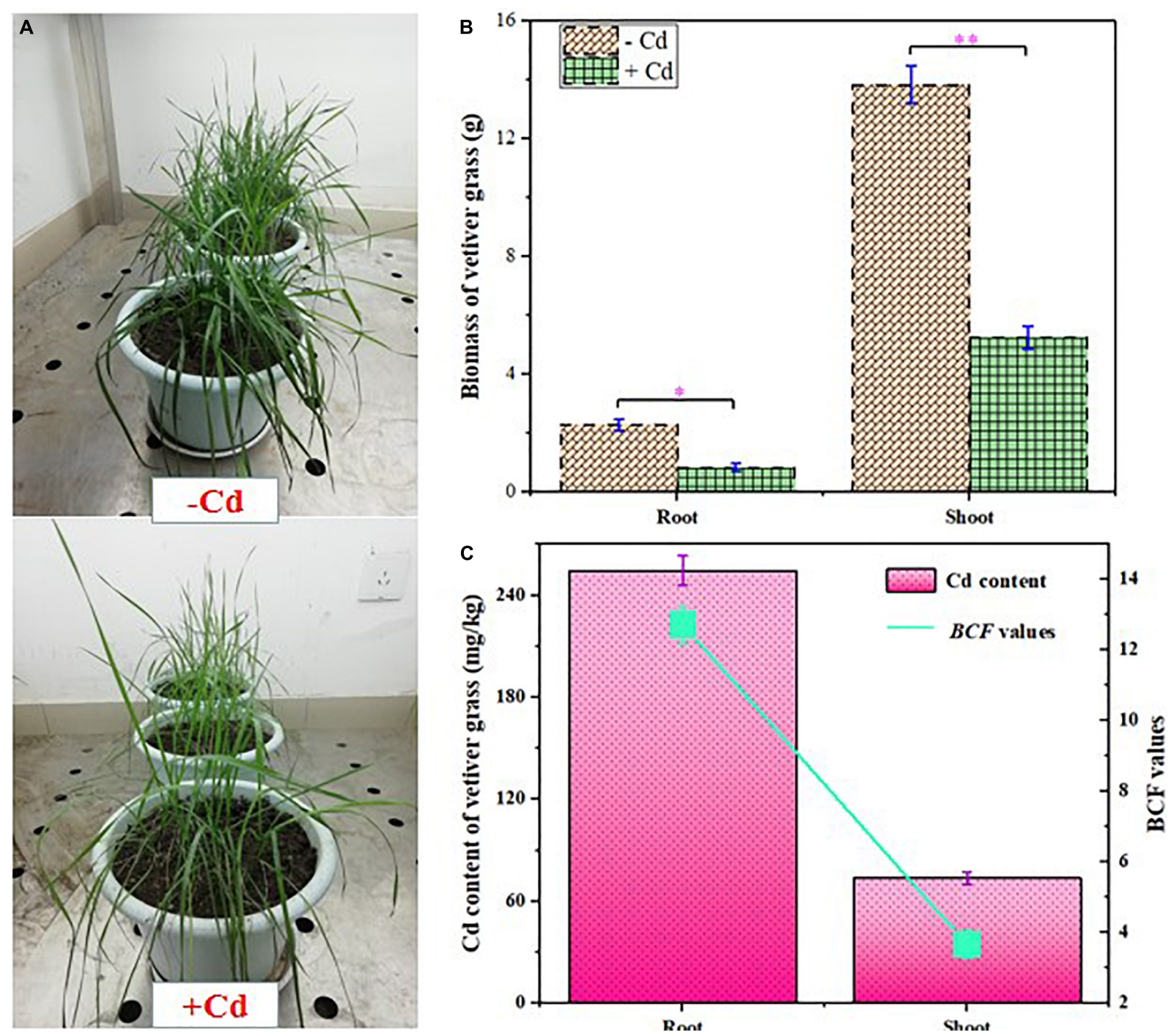

FIGURE 1 | Growth response (A), biomass (B), and cadmium (Cd) content and bioaccumulation factor (BCF) values (C) of Chrysopogon zizanioides. Error bars represent $S D$ values $(n=3) .{ }^{*}$ and ${ }^{* \star}$ represent $p<0.05$ and $p<0.01$, respectively.

\section{Response of Rhizospheric Microbial Community}

To reveal the changes of the microbial community in the rhizosphere in response to $\mathrm{Cd}$ toxicity, the rhizosphere microbiome of vetiver grass in $+\mathrm{Cd}$ and $-\mathrm{Cd}$ samples was analyzed by $16 \mathrm{~S}$ rRNA sequencing. A total of 1,016,862 highquality $16 \mathrm{~S}$ rRNA gene reads were obtained and clustered into 2,317 OTUs. Of these, 106 and 120 unique OTUs were observed in $-\mathrm{Cd}$ and $+\mathrm{Cd}$ samples, respectively (Supplementary Figure 1A). Rarefaction and Shannon curves tended to be plain (Supplementary Figures 1B,C), which indicated that the samples were suitable for further analysis (Wu et al., 2018). Alphadiversity indexes were widely used to evaluate microbial diversity (Xiao et al., 2017). It was observed that the alpha-diversity indexes, including Sobs, Shannon, Ace, and Chao, did not show a significant difference $(p<0.05)$ between $-\mathrm{Cd}$ and $+\mathrm{Cd}$ samples
(Supplementary Table 4), indicating that Cd toxicity did not significantly affect the rhizospheric microbial diversity.

The bacterial community structure in rhizosphere soil was analyzed, and the results are shown in Figure 2. The bacteria in rhizosphere soil were classified into 31 phyla (Figure 2A). The three dominant phyla across the samples were Actinobacteria, Proteobacteria, and Chloroflexi. The abundance of Actinobacteria was significantly higher than that of others, despite its percentage decreasing by $11.89 \%$ in the $+\mathrm{Cd}$ sample. In contrast, the proportion of Proteobacteria increased by $28.41 \%$ in the $+\mathrm{Cd}$ sample, compared to that in the-Cd sample. At the genus level (Figure 2B), there were 13 genera (apart from norank) with relative abundances higher than $1 \%$, and the three most abundant genera were Intrasporangium, Nocardioides, and Sphingomonas. Compared to the -Cd sample, the abundance of Intrasporangium decreased by $33.66 \%$, while that of Sphingomonas increased by 
29.59\% in the + Cd sample. Furthermore, the LEfSe tool was used to search biomarkers from phylum to genus level. Cladograms (Figure 2C) showed the different treatments, and the linear discriminant analysis scores of 3 or more were confirmed by LEfSe (Figure 2D). It was observed that a greater number of species were enriched in the $+\mathrm{Cd}$ sample compared to that in the-Cd sample. In the + Cd sample, when compared to the-Cd sample, it was observed that the abundances of Sphingomonas, Lysobacter, and Gemmatimonadetes significantly increased at the genus level by $29.73,131.21$, and $166.44 \%$, respectively.

In the Cd-contaminated soil, the toxicity of $\mathrm{Cd}$ led to the selection of microorganisms that are tolerant or resistant to $\mathrm{Cd}$ exposure (Valls and de Lorenzo, 2002). The dominant phyla in our study were Actinobacteria, Proteobacteria, and Chloroflexi, which were widely identified previously in southwestern China (Wu et al., 2018). Among the most relevant alteration in the bacterial community, in response to Cd stress, was a decrease in the abundance of Actinobacteria (Ai et al., 2018; Sarria Carabalí et al., 2020). Previous studies also found that Actinobacteria was the most dominant phylum in environments such as plant rhizosphere, sewage sludges, hot springs, and freshwater habitats (Alvarez et al., 2017; Xiao et al., 2017). The reduction in the abundance of Actinobacteria might be related to the elimination of Cd-sensitive bacteria belonging to the phylum Actinobacteria due to high Cd toxicity (Sarria Carabalí et al., 2020). The positive response of Proteobacteria against heavy metals has also been observed in various metal-contaminated environments, such as metal-polluted soils, metal mine sediments, and river sediments (Lorenz et al., 2006; Zhang et al., 2014). The increase in Proteobacteria abundance might be attributed to the complex ecology of its lower taxonomic groups, which can adapt to environmental changes more readily than other phyla (Sandaa et al., 2001). Besides, members of Proteobacteria are well known for their metal tolerance (Rajeev et al., 2021). Previous studies found that Proteobacteria abundance was positively correlated with Cd concentration in soils (Muehe et al., 2015; Xiao et al., 2017). In this study, interestingly, some bacterial genera such as Sphingomonas, Lysobacter, and Gemmatimonadetes were significantly enriched in the $+\mathrm{Cd}$ sample, and these genera are already known for their metal tolerance (Pan et al., 2016; Wang et al., 2020). This study, therefore, indicates that Cd exposure in the heavily contaminated soil can alter the rhizospheric microbial community at the phylum and genus levels.

\section{Response of Plant Transcriptome Transcriptome Assembly and Quantitative Real-Time PCR Validation}

To obtain a comparative overview of the transcriptome of plant roots and shoots, cDNA libraries were constructed from -Cd to + Cd samples and sequenced using the Illumina HiSeqTM 2000 platform. After the removal of low-quality reads, 0.287 billion raw reads from roots, 0.301 billion raw reads from shoots, 0.278 billion clean reads from roots, and 0.292 billion clean reads from shoots were obtained in this study (Supplementary Table 5). A total of 219,363 unigenes corresponding to 521,416 transcripts, varying from 201 to $16,062 \mathrm{bp}$, were obtained with an average size of 634.98 bp (Supplementary Table 6). In addition, the N50 and E90N50 of unigenes of assembled genes were 933 and 2,101, respectively, and the GC percentage was $50.37 \%$.

Venn diagram showed that a total of 36,868 unigenes were shared among groups (Figure 3A). A total of 10,117 and 4,893 unigenes from roots and shoots, respectively, were specifically expressed in the -Cd sample, and a total of 6,711 and 7,218 unigenes from roots and shoots, respectively, were specifically expressed in the $+\mathrm{Cd}$ sample. Heatmap (Figure 3B) showed a high similarity coefficient among plant root and shoot samples. Principal component analysis (PCA) (Figure 3C) showed that the first principal component (PC1) reached 39.51\%, which indicated a significantly different expression in shoots and roots. The second principal component (PC2) showed a significant difference in the unigene expression between the $-\mathrm{Cd}$ and $+\mathrm{Cd}$ samples. In addition, the quantitative real-time PCR (qRTPCR) transcriptome data from eight randomly selected genes suggested that RNA-Seq data obtained from the samples were reliable (Figure 3D).

\section{Identification and Functional Annotation of Differentially Expressed Genes in Response to Cadmium Stress}

The DESeq2 analysis was performed with a $p$-adjusted value $<0.05$ and a fold-change cutoff $>2$, in order to identify the DEGs between $-\mathrm{Cd}$ and $+\mathrm{Cd}$ samples (Supplementary Figure 2). In roots, a total of 880 DEGs, including 471 upregulated DEGs and 409 downregulated DEGs, were identified. Meanwhile, the number of DEGs in the shoots was higher than that in the roots, including 2,054 upregulated DEGs and 1,365 downregulated DEGs.

In this study, 161 upregulated genes from the roots and 755 overexpressed genes from the shoots fell within standard KEGG categories (Figure 4). Numerous overexpressed genes from shoots were associated with "translation" (40.53\%) and "replication and repair" (15.89\%). Various biological processes can be affected by Cd toxicity in plants, including genotoxicity and cytotoxicity. Genome stability is vital for DNA replication, gene expression, and protein synthesis in plant cells (Huang et al., 2019). Other studies have found that Cd appears to cause DNA damage mainly via the production of reactive oxygen species (ROS) and the inhibition of some DNA replication or repair enzymes, which could destabilize the genome and disturb the DNA replication system, e.g., by affecting mismatch repair (MMR), nucleotide excision repair (NER), and base excision repair (BER) (Gao et al., 2013; Tan et al., 2017). These genes involved in "translation" and "replication and repair" pathways were upregulated by Cd stress, possibly as a part of tolerance mechanisms to address Cd genotoxicity, in C. zizanioides. In particular, numerous overexpressed genes in shoots and roots were associated with "ribosome," which might play an essential role in the Cd detoxification in C. zizanioides, because the ribosome plays a central role in protein synthesis (Xu et al., 2015). Apart from shoots, numerous overrepresented genes in roots were involved in "Phenylpropanoid biosynthesis," "Plant-pathogen interaction," "MAPK signaling pathway-plant," and "Phagosome" pathways (Figure 4). These genes mainly 


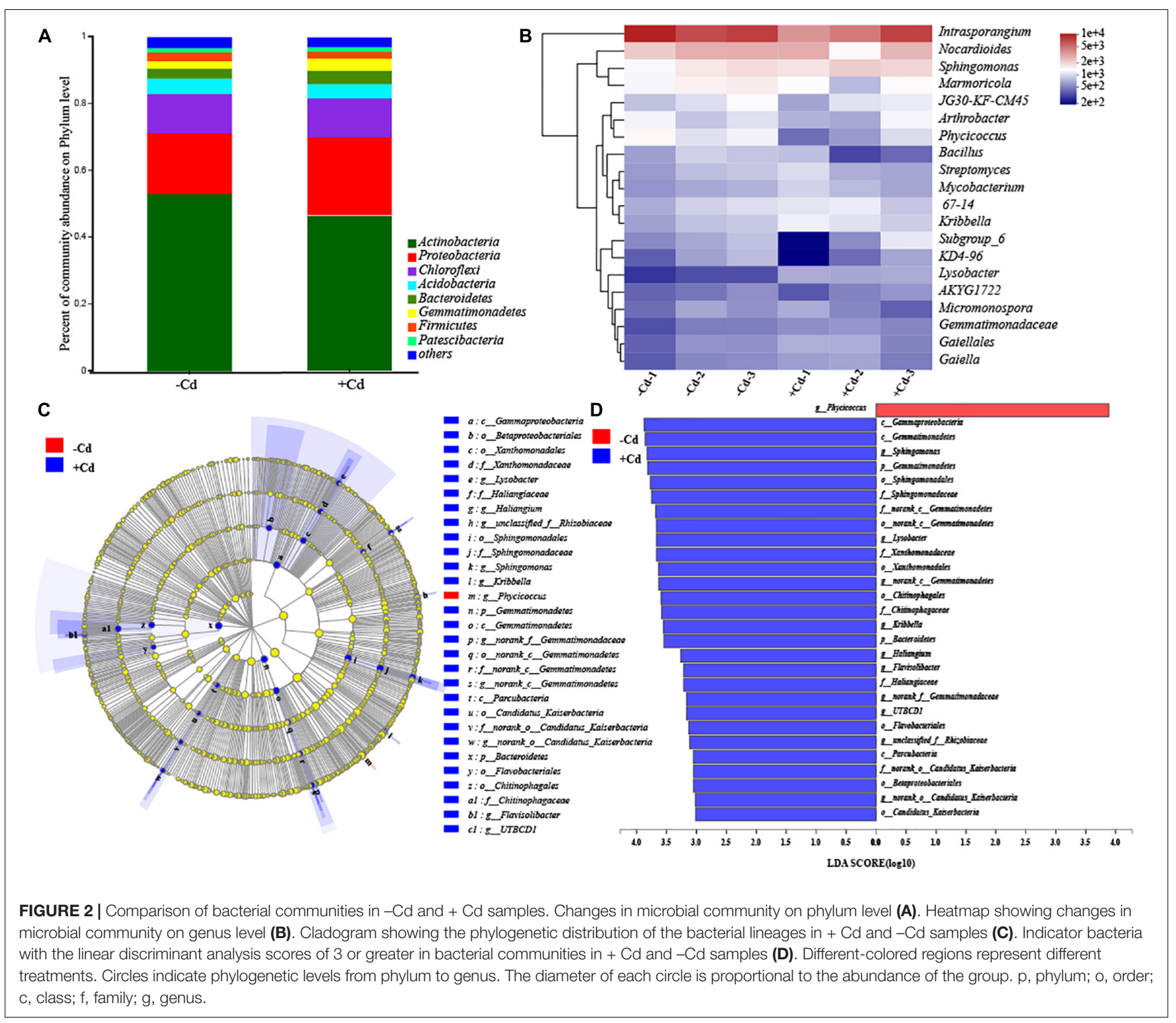

coded regulatory and functional proteins, participating in signal transduction and functional regulation in plants under Cd stress (Li et al., 2018). Furthermore, GO enrichment showed that the upregulated DEGs in roots and shoots were both enriched in the $-\mathrm{Cd}$ vs. + Cd group and were involved in catalytic activity, transferase activity, metal ion binding, and antioxidant activity (Supplementary Tables 7, 8). These results further reveal the gene functional response of C. zizanioides under Cd stress.

\section{Differentially Expressed Genes Analysis in Relation to Cadmium Detoxification in Chrysopogon zizanioides}

Transcriptomic analysis showed that the upregulated DEGs were mainly involved in redox homeostasis, GSH metabolism, cell wall biogenesis, and transmembrane transport pathways (Figure 5).

In this study, 24 genes from roots and 34 genes from shoots associated with redox homeostasis were upregulated under $\mathrm{Cd}$ exposure, and most of these encode oxidases and reductases, such as peroxidase, monooxygenase, and cytochrome P450 (Supplementary Table 9). A total of 11 and 6 DEGs associated with peroxidase were identified in roots and shoots, and their maximum $\log _{2} \mathrm{FC}$ values reached 5.78 and 9.85, respectively. However, DEGs between roots and shoots involved in redox homeostasis also showed a significant difference. Most DEGs in roots were associated with oxidase regulation and cytochrome P450, and the DEGs associated with peroxidase were especially enhanced. These results were consistent with our previous study, which demonstrated that antioxidase activities played an important role in $\mathrm{Cd}$ resistance in C. zizanioides (Wu et al., 2020). The intracellular redox homeostasis in plants is easily influenced by environmental stress (Hassan et al., 2005). Exposure to Cd can increase oxidative stress in plants by increasing the production of ROS, which can cause severe damage to major cellular macromolecules such as proteins, lipids, and DNA (Eckardt, 2008). The signal transduction pathways 

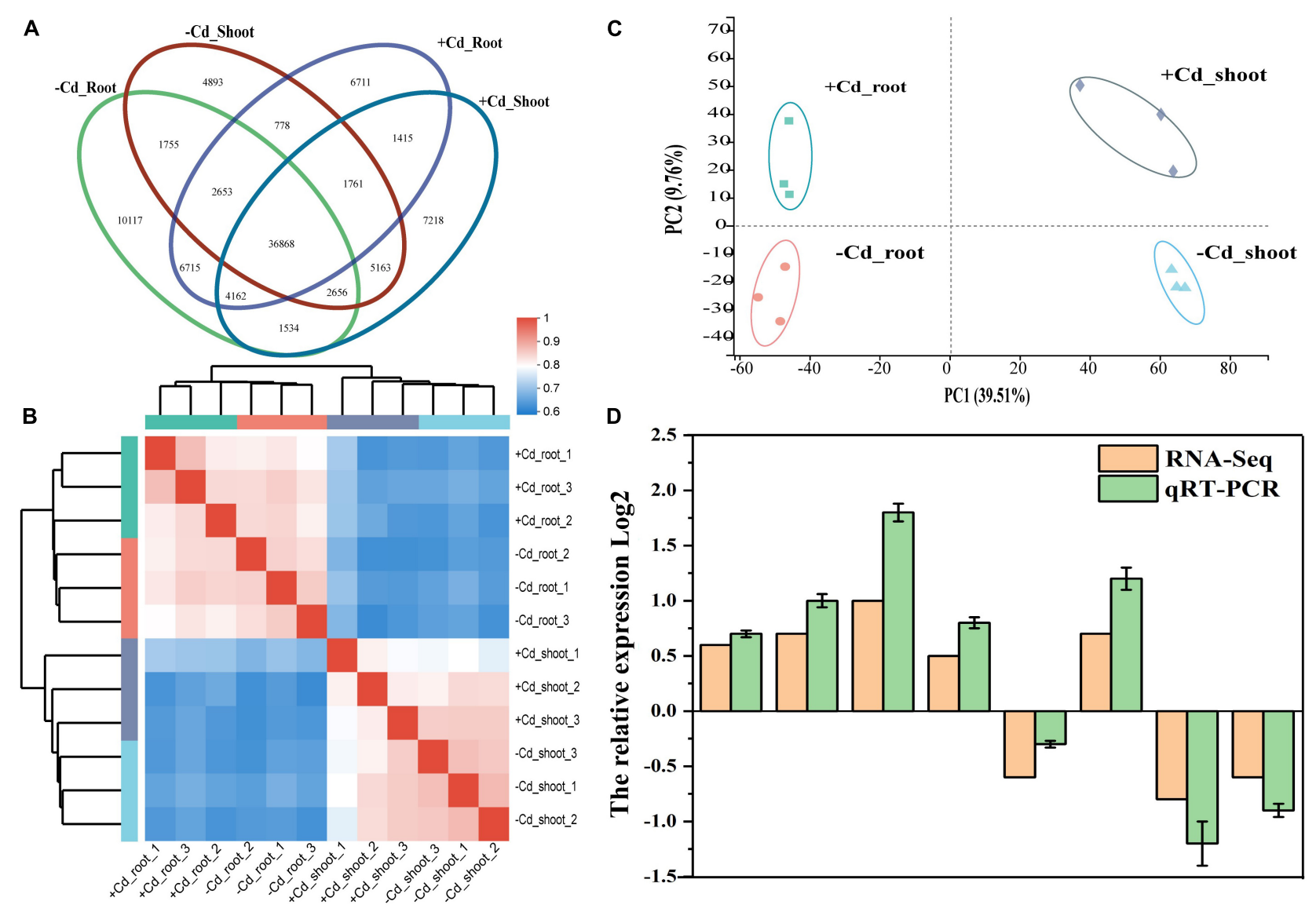

FIGURE 3 | Venn diagram (A), heatmap tree of groups (B), principal component analysis (PCA) (C), and quantitative real-time PCR (qRT-PCR) validation (D) of plant transcriptome.

triggered in response to ROS stress can modulate the expression of specific downstream genes involved in plant detoxification. In addition, the antioxidant enzymes, including peroxidase, thioredoxin, oxidoreductase, GSH transferase, and catalase, are produced to reduce ROS-induced damage in plants (Mittler et al., 2004). Studies have also found that cytochrome P450 ameliorates Cd toxicity in plants by participating in fatty acyl metabolism, plant hormone synthesis, and secondary metabolite synthesis, thus enhancing stress response (Baker et al., 2001; Reynders et al., 2006). Moreover, our study found that numerous DEGs in shoots were connected to reductases, including ribonucleoside diphosphate reductase and 3-oxoacyl-CoA reductase, which are known to participate in DNA synthesis and energy regulation in plants (Coppey, 1977; Wengenmayer et al., 2010).

Glutathione metabolism might be a critical pathway for plant survival because GSH plays an essential role in the GSH-ascorbate redox system, which can effectively ameliorate hydrogen peroxide toxicity (Foyer and Noctor, 2011). Moreover, GSH is the precursor of plant peptides and GSH oligomers that can chelate heavy metals and transfer them into the vacuole, thus ameliorating metal toxicity (Dubey et al., 2016). In this study, 5 genes encoding GSH-S-transferase (GST) were overexpressed in response to $\mathrm{Cd}$ stress, and the maximum $\log _{2} \mathrm{FC}$ reached
8.80 (Supplementary Table 10). GSTs are a superfamily of multifunctional enzymes that play crucial roles in the metabolism and intracellular homeostasis of GSH, such as catalyzing the binding of sulfhydryl groups and heavy metals or metalloids, for detoxification (Nianiou-Obeidat et al., 2017). Therefore, the increased expression of GSTs may help C. zizanioides in the process of Cd accumulation.

Roots are the first plant tissue to sense soil stress and also the first barrier preventing non-essential elements from entering the plant (Claire-Lise et al., 2015). Therefore, roots play a key role in helping plants reduce the toxicity of heavy metals and maintain their homeostasis (Lux et al., 2011). When heavy metals enter roots and shoots, most of them can be chelated and coprecipitated by polysaccharides such as lignin, cellulose, and hemicellulose, in the cell wall. During this process, some enzymes such as cellulase and glucanase can participate in cell wall biogenesis, thus contributing to heavy metal resistance (Huang et al., 2019). In this study, four overexpressed genes associated with xylanase inhibitor N-terminal, three overexpressed genes associated with glycosyl hydrolases, and one overexpressed gene associated with cellulose synthase were identified in the roots; but few genes involved in cell wall biosynthesis were overexpressed in shoots (Supplementary Table 11). In roots, most of the genes 


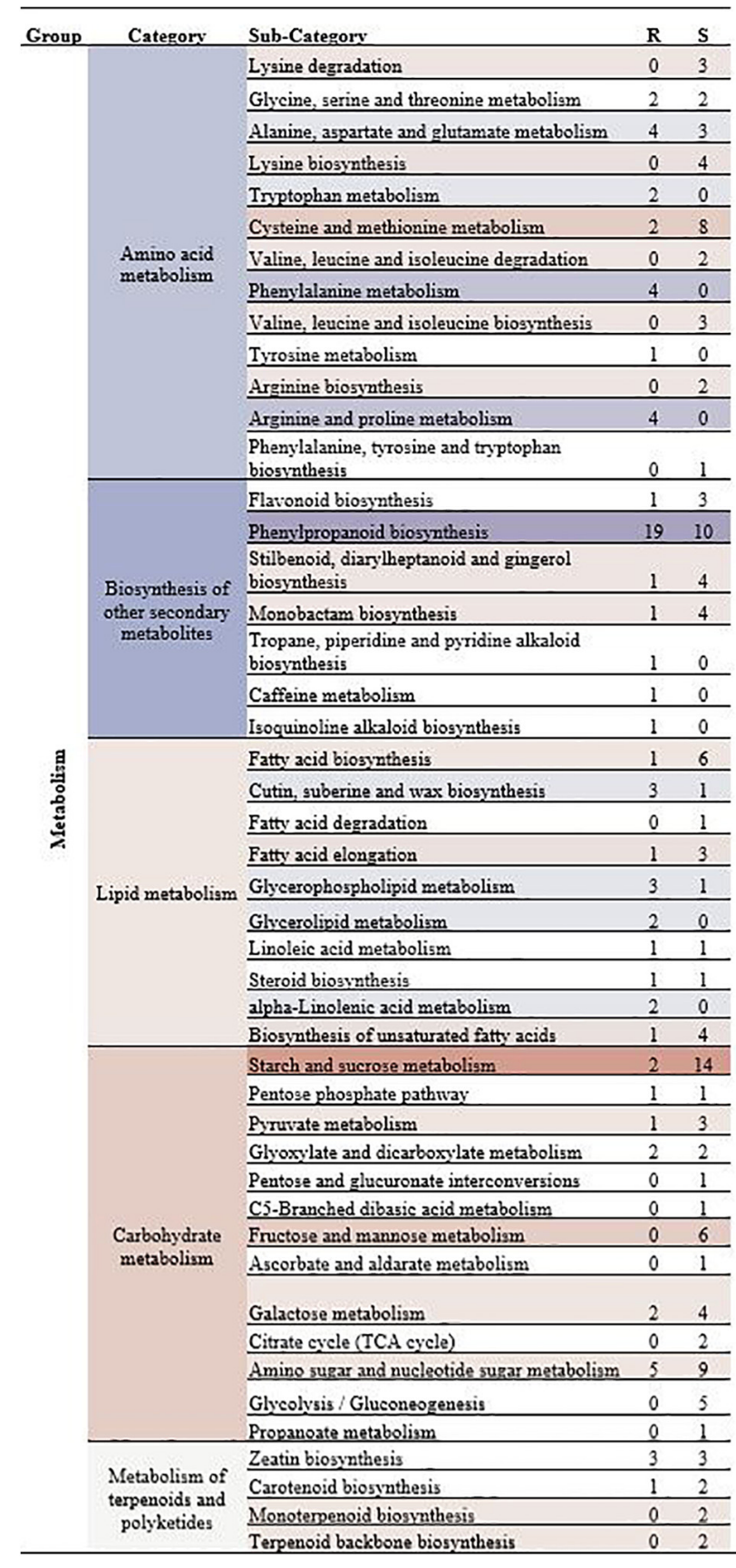

\begin{tabular}{|c|c|c|c|}
\hline Group & Category & Sub-Category & R $\mathbf{S}$ \\
\hline \multirow{21}{*}{ 鴶 } & \multirow{5}{*}{$\begin{array}{l}\text { Metabolism } \\
\text { of cofactors } \\
\text { and vitamins }\end{array}$} & Porghyrin and chlorophyll metabolism & 11 \\
\hline & & Biotin metabolism & 0 \\
\hline & & One carbon pool by folate & 0 \\
\hline & & Pantothenate and CoA biosynthesis & 0 \\
\hline & & Ubiquinone and other terpenoid-quinone biosynthesis & 2 \\
\hline & \multirow{5}{*}{$\begin{array}{l}\text { Metabolism } \\
\text { of other } \\
\text { amino acids }\end{array}$} & Cyanoamino acid metabolism & 0 \\
\hline & & beta-Alanine metabolism & 1 \\
\hline & & Selenocompound metabolism & 0 \\
\hline & & Glutathione metabolism & 3 \\
\hline & & Glutathione metabolism & 3 \\
\hline & \multirow{4}{*}{$\begin{array}{l}\text { Energy } \\
\text { metabolism }\end{array}$} & Oxidative phosphorylation & 1 \\
\hline & & Nitrogen metabolism & 1 \\
\hline & & Carbon fixation in photossnthatic organisms & $0 \quad 1$ \\
\hline & & Sulfur metabolism & 30 \\
\hline & \multirow{5}{*}{$\begin{array}{l}\text { Glycan } \\
\text { biosynthesis } \\
\text { and } \\
\text { metabolism }\end{array}$} & N-Glycan biosynthesis & 0 \\
\hline & & Other glycan degradation & 1 \\
\hline & & Glycosphingolipid biosynthesis - ganglio series & 1 \\
\hline & & Glycosphingolipid biosynthesis - globo and isoglobo series & 1 \\
\hline & & Glycosaminoglycan degradation & 10 \\
\hline & \multirow{2}{*}{$\begin{array}{l}\text { Nucleotide } \\
\text { metabolism }\end{array}$} & Purine metabolism & $2 \quad 29$ \\
\hline & & Pyrimidime metabolism & $0 \quad 33$ \\
\hline \multirow{17}{*}{ 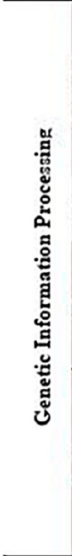 } & \multirow{5}{*}{$\begin{array}{l}\text { Folding, } \\
\text { sorting and } \\
\text { degradation }\end{array}$} & SNARE interactions in vesicular transport & $0 \quad 1$ \\
\hline & & Protein export & 11 \\
\hline & & Ubiquitin mediated proteolygis & $0 \quad 12$ \\
\hline & & RNA degradation & 123 \\
\hline & & Protein processing in endoplasmic reticulum & $5 \quad 4$ \\
\hline & \multirow{2}{*}{ Transcription } & Basal transcription factors & 0 \\
\hline & & Spliceosome & $2 \quad 22$ \\
\hline & \multirow{4}{*}{ Translation } & Aminoscyl-tRNA biosynthesis & 05 \\
\hline & & Ribosome biogenesis in eukaryotes & $0 \quad 50$ \\
\hline & & Ribosome & 16226 \\
\hline & & RNA transport & $3 \quad 25$ \\
\hline & \multirow{6}{*}{$\begin{array}{l}\text { Replication } \\
\text { and repair }\end{array}$} & mRNA surveillance pathway & 19 \\
\hline & & Mismatch repair & $1 \quad 21$ \\
\hline & & Nucleotide excision repair & 120 \\
\hline & & DNA replication & \\
\hline & & Non-homologous end-joining & 0 \\
\hline & & Homolozous recombination & 129 \\
\hline \multirow{4}{*}{$\begin{array}{l}\text { 离 } \\
\text { 它 }\end{array}$} & $\begin{array}{l}\text { Membrane } \\
\text { transport }\end{array}$ & $A B C$ transporters & 1 \\
\hline & \multirow{3}{*}{$\begin{array}{l}\text { Signal } \\
\text { transduction }\end{array}$} & MAPK signaling pathway - plant & $7 \quad 12$ \\
\hline & & Phogphatidvlinositol signaling svstem & 21 \\
\hline & & Plant hormone gignal transduction & $1 \quad 10$ \\
\hline \multirow{3}{*}{ తُ่ } & \multirow{3}{*}{$\begin{array}{l}\text { Transport and } \\
\text { catabolism }\end{array}$} & Phagosome & 76 \\
\hline & & Endocytosis & 1 \\
\hline & & Peroxisome & 21 \\
\hline \multirow{2}{*}{ Syz. } & \multirow{2}{*}{$\begin{array}{l}\text { Envi. } \\
\text { adaptation }\end{array}$} & Plant-pathogen interaction & $s$ \\
\hline & & Circadian rhythm - plant & 0 \\
\hline
\end{tabular}

FIGURE 4 | Normalized transcript expression comparison of root (R) and shoot (S) by + Cd vs. -Cd binned into the Kyoto Encyclopedia of Genes and Genomes (KEGG) categories. Genes only represented when DESeq2 $p$-adjusted value $<0.05$ and the fold ratio $>2$. Numbers in the category column represent the number of genes showing higher expression in the R or S, and the color shading is based on the difference between the expression in R and $\mathrm{S}$ (overrepresented in $\mathrm{S}$, red; overrepresented in R, blue).

involved in cell wall biosynthesis were highly upregulated, and the maximum $\log _{2} \mathrm{FC}$ reached 7.84 . These results were positively correlated with $\mathrm{Cd}$ accumulation in plant roots (Figure 1), indicating that cell wall biogenesis contributes to higher $\mathrm{Cd}$ accumulation in C. zizanioides roots than that in shoots.

Furthermore, transmembrane transporters have been reported to play a crucial role in the uptake and transport of metal ions in plants (Aibara and Miwa, 2014). In response to Cd stress, 16 and 8 genes encoding transmembrane transporters were upregulated in roots and shoots, respectively, including inorganic phosphate transporters, $\mathrm{ABC}$ transporters, and zinc transporters (Supplementary Table 12). In addition, the expression of upregulated genes in roots $\left(\log _{2} \mathrm{FC} 2.15-9.20\right)$ was significantly higher than that in shoots $\left(\log _{2} \mathrm{FC} 2.21-3.95\right)$, which might be 


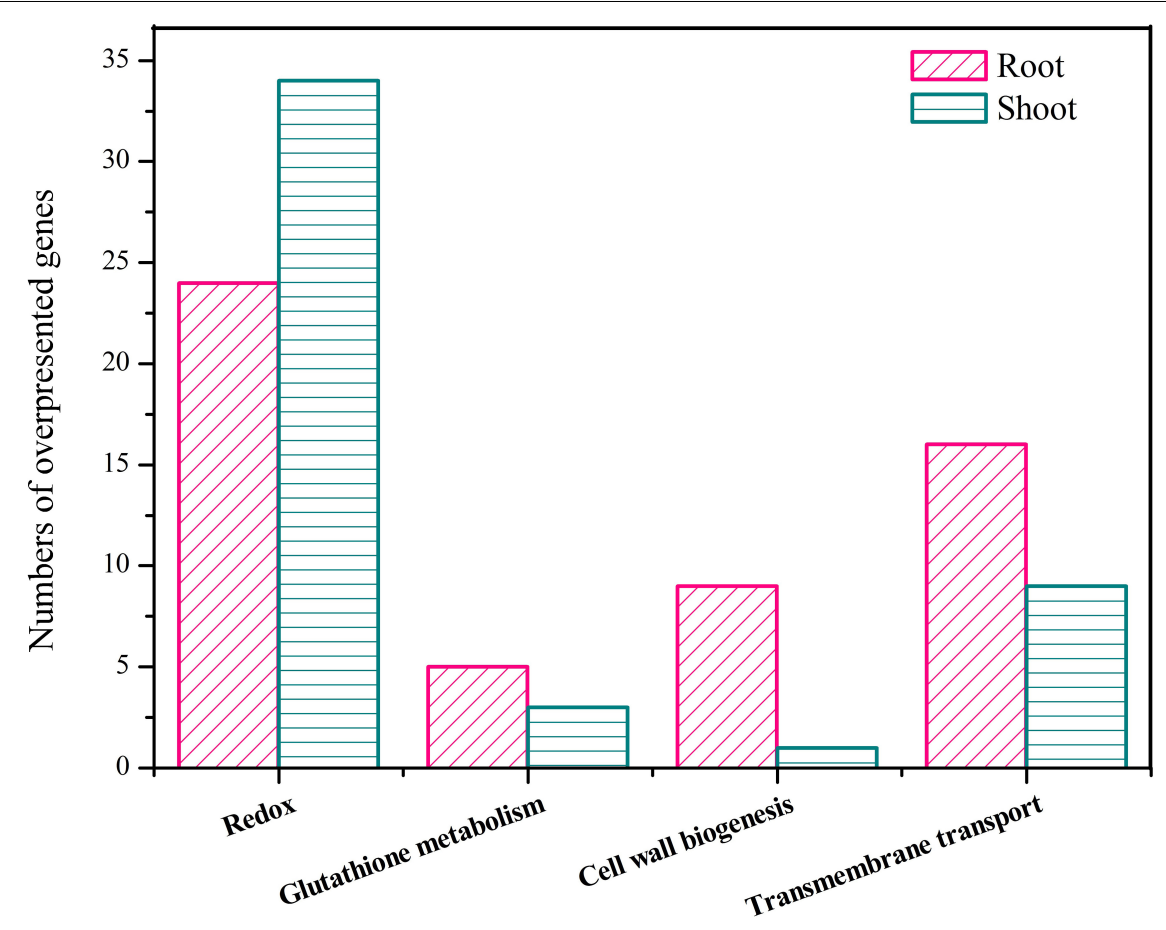

FIGURE $\mathbf{5}$ | Number of overexpressed genes participating in redox homeostasis, glutathione metabolism, cell wall biosynthesis, and transmembrane transport.

caused by the extent of Cd accumulation. Studies have suggested that ABC transporters such as OsHMA3 (Takahashi et al., 2012), OsABCC (Song et al., 2014), AtABCC1 (Patrizia et al., 2015), and AtABCC2 (Huang et al., 2019) are mainly located in the vacuolar membrane and could transport $\mathrm{Cd}$ into the vacuole, thus reducing Cd toxicity. Regional isolation of $\mathrm{Cd}$ may therefore be an important mechanism for plant detoxification.

\section{Possible Interaction Between Rhizospheric Microbial Communities and Plant Transcriptome}

Previous studies found that the alteration of microbial communities under $\mathrm{Cd}$ stress increased the secretion of organic acids such as tartaric acid, malic acid, oxalic acid, and succinic acid, by microorganisms (Wang et al., 2021). These organic acids are known to affect the levels of minerals and metals in plants (Yuan et al., 2007). For example, oxalic acid and tartaric acid play a role in the rhizosphere by altering the $\mathrm{pH}$ of rhizospheric soil from 7.00 to 2.65 and by increasing the bioavailability of heavy metals from 8 to $96 \%$ (Li et al., 2010). In this study, Sphingomonas, Lysobacter, and Gemmatimonadetes were significantly enriched in the $+\mathrm{Cd}$ samples (Figure 2C). Sphingomonas has been previously found to be abundant in Cd-contaminated rhizospheric soil (Zhao et al., 2017). Most Sphingomonas are metal-activated strains, which can enhance Cd bioavailability by secreting organic acids (Wang et al., 2019). Chen et al. (2014) found that the incubation with Sphingomonas significantly enhanced Cd uptake by $S$. alfredii. In addition, Sphingomonas was frequently associated with dynamic biogeochemical processes such as iron or sulfate cycling, resulting in the release of dissolved $\mathrm{Cd}$ by sulfur oxidation (Wang et al., 2021). Consistent with other studies, Cd stress appeared to increase the relative abundance of Lysobacter in rhizospheric soil in this study (Li et al., 2022). Lysobacter are plant growth-promoting bacteria that can resist various pathogens and produce phytohormones, which could increase the uptake of heavy metals by accumulators (Laborda et al., 2020). Plant transcriptome factors control the entry of Cd from the soil into plant tissues ( $\mathrm{Su}$ et al., 2021). The alteration of rhizospheric microbiology, due to the factors such as Cd stress, directly influences the plant transcriptome (Gu et al., 2019). The enrichment of Sphingomonas and Lysobacter in rhizospheric soil could increase Cd bioavailability and plant tolerance, which might be another reason why the genes associated with $\mathrm{Cd}$ tolerance and uptake, including those responsible for redox homeostasis, GSH metabolism, cell wall biogenesis, and transmembrane transport, are upregulated under Cd stress.

\section{CONCLUSION}

This study revealed the impact of $\mathrm{Cd}$ exposure on the rhizospheric microbial community and transcriptome of C. zizanioides. C. zizanioides showed a great capacity for Cd accumulation, and its BCF value in roots reached 12.54, indicating a high capability to immobilize $\mathrm{Cd}$ in soil. On Cd exposure, the rhizospheric microbial community in C. zizanioides was significantly altered, resulting in a significant enrichment of Sphingomonas, Lysobacter, and Gemmatimonadetes. Meanwhile, 
Cd exposure significantly changed the transcriptome of C. zizanioides roots and shoots, and the overexpressed genes associated with redox homeostasis, GSH metabolism, cell wall biogenesis, and transmembrane transport had important effects on the Cd detoxification process in C. zizanioides.

\section{DATA AVAILABILITY STATEMENT}

The datasets presented in this study can be found in online repositories. The names of the repository/repositories and accession number(s) can be found below: https://www.ncbi.nlm. nih.gov/, PRJNA772523.

\section{AUTHOR CONTRIBUTIONS}

BW designed the project and performed the experiments. JL performed the statistical analysis and edited the manuscript. DP, ZW, and HX participated in the research and analyzed the data. All authors read and approved the final manuscript.

\section{REFERENCES}

Ai, C., Zhang, S., Zhang, X., Guo, D., Zhou, W., and Huang, S. (2018). Distinct responses of soil bacterial and fungal communities to changes in fertilization regime and crop rotation. Geoderma 319, 156-166.

Aibara, I., and Miwa, K. (2014). Strategies for optimization of mineral nutrient transport in plants: multilevel regulation of nutrient-dependent dynamics of root architecture and transporter activity. Plant Cell Physiol. 55, 2027-2036. doi: $10.1093 / \mathrm{pcp} / \mathrm{pcu} 156$

Aibibu, N., Liu, Y., Zeng, G., Wang, X., Chen, B., Song, H., et al. (2010). Cadmium accumulation in Vetiveria zizanioides and its effects on growth, physiological and biochemical characters. Bioresour. Technol. 101, 6297-6303. doi: 10.1016/j. biortech.2010.03.028

Alvarez, A., Saez, J. M., Davila Costa, J. S., Colin, V. L., Fuentes, M. S., Cuozzo, S. A., et al. (2017). Actinobacteria: current research and perspectives for bioremediation of pesticides and heavy metals. Chemosphere 166, 41-62. doi: 10.1016/j.chemosphere.2016.09.070

Attinti, R., Barrett, K. R., Datta, R., and Sarkar, D. (2017). Ethylenediaminedisuccinic acid (EDDS) enhances phytoextraction of lead by vetiver grass from contaminated residential soils in a panel study in the field. Environ. Pollut. 225, 524-533. doi: 10.1016/j.envpol.2017.01.088

Baker, J. R., Satarug, S., Reilly, P. E., Edwards, R. J., Ariyoshi, N., Kamataki, T., et al. (2001). Relationships between non-occupational cadmium exposure and expression of nine cytochrome $\mathrm{P} 450$ forms in human liver and kidney cortex samples. Biochem. Pharmacol. 62, 713-721. doi: 10.1016/s0006-2952(01)00 716-x

Chen, B., Zhang, Y., Rafiq, M. T., Khan, K. Y., Pan, F., Yang, X., et al. (2014). Improvement of cadmium uptake and accumulation in Sedum alfredii by endophytic bacteria Sphingomonas SaMR12: effects on plant growth and root exudates. Chemosphere 117, 367-373. doi: 10.1016/j.chemosphere.2014.07.078

Chen, P., Chen, T., Li, Z., Jia, R., Luo, D., Tang, M., et al. (2020). Transcriptome analysis revealed key genes and pathways related to cadmium-stress tolerance in kenaf (Hibiscus cannabinus L.). Ind. Crops Prod. 158:112970.

Chen, S., Zhou, Y., Chen, Y., and Gu, J. (2018). fastp: an ultra-fast all-in-one FASTQ preprocessor. Bioinformatics 34, i884-i890. doi: 10.1093/bioinformatics/bty560

Claire-Lise, M., Michal, J., Stéphanie, H., Elena, C. R., Pietro, S., Marie-Pierre, I., et al. (2015). Intraspecific variability of cadmium tolerance and accumulation, and cadmium-induced cell wall modifications in the metal hyperaccumulator Arabidopsis halleri. J. Exp. Bot. 66, 3215-3227. doi: 10.1093/jxb/erv144

\section{FUNDING}

This study was financially supported by the National Key Research and Development Program (2018YFC1802605), the Science and Technology Program of Sichuan Province (2022ZDYF0281), the Chengdu Science and Technology Project (2021-YF05-00195-SN), and the State Environmental Protection Key Laboratory of Synergetic Control and Joint Remediation for Soil and Water Pollution (GHBK-2020-012).

\section{ACKNOWLEDGMENTS}

We would like to thank Guanglei Cheng and Tingting He from Sichuan University for their technical assistance.

\section{SUPPLEMENTARY MATERIAL}

The Supplementary Material for this article can be found online at: https://www.frontiersin.org/articles/10.3389/fpls.2022. 808844/full\#supplementary-material

Conesa, A., Götz, S., García-Gómez, J. M., Terol, J., Talón, M., and Robles, M. (2005). Blast2GO: a universal tool for annotation, visualization and analysis in functional genomics research. Bioinformatics 21, 3674-3676. doi: 10.1093/ bioinformatics/bti610

Coppey, J. (1977). Common precursor pathways of Herpes DNA and of repair synthesis in ultraviolet irradiated cells. Nature 265, 260-261. doi: 10.1038/ 265260a 0

Cui, H., Li, H., Zhang, S., Yi, Q., Zhou, J., Fang, G., et al. (2020). Bioavailability and mobility of copper and cadmium in polluted soil after phytostabilization using different plants aided by limestone. Chemosphere 242:125252. doi: 10.1016/j. chemosphere.2019.125252

Dubey, A. K., Kumar, N., Sahu, N., Verma, P. K., Ranjan, R., Chakrabarty, D., et al. (2016). Response of two rice cultivars differing in their sensitivity towards arsenic, differs in their expression of glutaredoxin and glutathione $\mathrm{S}$ transferase genes and antioxidant usage. Ecotoxicol. Environ. Saf. 124, 393-405. doi: 10. 1016/j.ecoenv.2015.10.017

Eckardt, N. A. (2008). Oxylipin signaling in plant stress responses. Plant Cell 20, 495-497. doi: 10.1105/tpc.108.059485

Edgar, R. C. (2013). Uparse: highly accurate OTU sequences from microbial amplicon reads. Nat. Methods 10, 996-998. doi: 10.1038/nmeth.2604

Foyer, C. H., and Noctor, G. (2011). Ascorbate and glutathione: the heart of the redox hub. Plant Physiol. 155, 2-18. doi: 10.1104/pp.110.167569

Gao, J., Sun, L., Yang, X., and Liu, J. X. (2013). Transcriptomic analysis of cadmium stress response in the heavy metal hyperaccumulator Sedum alfredii hance. PLoS One 8:64643. doi: 10.1371/journal.pone.0064643

Gao, Y., Miao, C., Mao, L., Zhou, P., Jin, Z., and Shi, W. (2010). Improvement of phytoextraction and antioxidative defense in Solanum nigrum L. under cadmium stress by application of cadmium-resistant strain and citric acid. J. Hazard. Mater. 181, 771-777. doi: 10.1016/j.jhazmat.2010.05.080

Grabherr, M. G., Haas, B. J., Yassour, M., Levin, J. Z., Thompson, D. A., Amit, I., et al. (2011). Full-length transcriptome assembly from RNA-Seq data without a reference genome. Nat. Biotechnol. 29, 644-652. doi: 10.1038/nbt.1883

Gu, L., Zhao, M., Ge, M., Zhu, S., Cheng, B., and Li, X. (2019). Transcriptome analysis reveals comprehensive responses to cadmium stress in maize inoculated with arbuscular mycorrhizal fungi. Ecotoxicol. Environ. Saf. 186:109744. doi: 10.1016/j.ecoenv.2019.109744

Hassan, M. J., Shao, G., and Zhang, G. (2005). Influence of cadmium toxicity on growth and antioxidant enzyme activity in rice cultivars with different grain cadmium accumulation. J. Plant Nutr. 28, 1259-1270. 
Hemme, C. L., Deng, Y., Gentry, T. J., Fields, M. W., Wu, L., Barua, S., et al. (2010). Metagenomic insights into evolution of a heavy metal-contaminated groundwater microbial community. ISME J. 4, 660-672. doi: 10.1038/ismej. 2009.154

Hu, L., Robert, C. A. M., Cadot, S., Zhang, X., Ye, M., Li, B., et al. (2018). Root exudate metabolites drive plant-soil feedbacks on growth and defense by shaping the rhizosphere microbiota. Nat. Commun. 9:2738. doi: 10.1038/ s41467-018-05122-7

Huang, Y., Chen, H., Reinfelder, J. R., Liang, X., Sun, C., Liu, C., et al. (2019). A transcriptomic (RNA-seq) analysis of genes responsive to both cadmium and arsenic stress in rice root. Sci. Total Environ. 666, 445-460. doi: 10.1016/ j.scitotenv.2019.02.281

Imseng, M., Wiggenhauser, M., Keller, A., Müller, M., Rehkämper, M., Murphy, K., et al. (2018). Fate of Cd in agricultural soils: a stable isotope approach to anthropogenic impact, soil formation, and soil-plant cycling. Environ. Sci. Technol. 52, 1919-1928. doi: 10.1021/acs.est.7b05439

Jiang, B., Adebayo, A., Jia, J., Xing, Y., Deng, S., Guo, L., et al. (2019). Impacts of heavy metals and soil properties at a Nigerian e-waste site on soil microbial community. J. Hazard. Mater. 362, 187-195. doi: 10.1016/j.jhazmat.2018.08. 060

Kang, B., Bowatte, S., and Hou, F. (2021). Soil microbial communities and their relationships to soil properties at different depths in an alpine meadow and desert grassland in the Qilian mountain range of China. J. Arid Environ. 184:104316. doi: 10.1016/j.jaridenv.2020.104316

Khan, M. A., Khan, S., Khan, A., and Alam, M. (2017). Soil contamination with cadmium, consequences and remediation using organic amendments. Sci. Total Environ. 601-602, 1591-1605. doi: 10.1016/j.scitotenv.2017.06.030

Laborda, P., Chen, X., Wu, G., Wang, S., Lu, X., Ling, J., et al. (2020). Lysobacter gummosus $\mathrm{OH} 17$ induces systemic resistance in Oryza sativa "Nipponbare". Plant Pathol. 69, 838-848.

Li, B., and Dewey, C. N. (2011). RSEM: accurate transcript quantification from RNA-Seq data with or without a reference genome. BMC Bioinformatics 12:323. doi: 10.1186/1471-2105-12-323

Li, Q., Huang, W., Xiong, C., and Zhao, J. (2018). Transcriptome analysis reveals the role of nitric oxide in Pleurotus eryngii responses to $\mathrm{Cd}^{2+}$ stress. Chemosphere 201, 294-302. doi: 10.1016/j.chemosphere.2018.03.011

Li, W. C., Ye, Z. H., and Wong, M. H. (2010). Metal mobilization and production of short-chain organic acids by rhizosphere bacteria associated with a $\mathrm{Cd} / \mathrm{Zn}$ hyperaccumulating plant, Sedum alfredii. Plant Soil 326, 453-467.

Li, X., Li, Y., Zhu, X., Gui, X., Ma, C., Peng, W., et al. (2022). Evaluation of the cadmium phytoextraction potential of tobacco (Nicotiana tabacum) and rhizosphere micro-characteristics under different cadmium levels. Chemosphere 286:131714. doi: 10.1016/j.chemosphere.2021.131714

Liu, H., Wang, C., Xie, Y., Luo, Y., Sheng, M., Xu, F., et al. (2020). Ecological responses of soil microbial abundance and diversity to cadmium and soil properties in farmland around an enterprise-intensive region. J. Hazard. Mater. 392:122478. doi: 10.1016/j.jhazmat.2020.122478

Liu, L., Li, W., Song, W., and Guo, M. (2018). Remediation techniques for heavy metal-contaminated soils: principles and applicability. Sci. Total Environ. 633, 206-219. doi: 10.1016/j.scitotenv.2018.03.161

Lorenz, N., Hintemann, T., Kramarewa, T., Katayama, A., Yasuta, T., Marschner, P., et al. (2006). Response of microbial activity and microbial community composition in soils to long-term arsenic and cadmium exposure. Soil Biol. Biochem. 38, 1430-1437.

Lux, A., Martinka, M., Vaculík, M., and White, P. J. (2011). Root responses to cadmium in the rhizosphere: a review. J. Exp. Bot. 62, 21-37. doi: 10.1093/jxb/ erq281

Mittler, R., Vanderauwera, S., Gollery, M., and Van Breusegem, F. V. (2004). Reactive oxygen gene network of plants. Trends Plant Sci. 9, 490-498.

Muehe, E. M., Weigold, P., Adaktylou, I. J., Planer-Friedrich, B., Kraemer, U., Kappler, A., et al. (2015). Rhizosphere microbial community composition affects cadmium and zinc uptake by the metal-hyperaccumulating plant Arabidopsis halleri. Appl. Environ. Microbiol. 81, 2173-2181. doi: 10.1128/AEM. 03359- 14

Nianiou-Obeidat, I., Madesis, P., Kissoudis, C., Voulgari, G., Chronopoulou, E., Tsaftaris, A., et al. (2017). Plant glutathione transferase-mediated stress tolerance: functions and biotechnological applications. Plant Cell Rep. 36, 791-805. doi: 10.1007/s00299-017-2139-7
O’Connor, D., Peng, T., Zhang, J., Tsang, D. C. W., Alessi, D. S., Shen, Z., et al. (2018). Biochar application for the remediation of heavy metal polluted land: a review of in situ field trials. Sci. Total Environ. 619-620, 815-826. doi: 10.1016/ j.scitotenv.2017.11.132

Ogata, H., Goto, S., Sato, K., Fujibuchi, W., Bono, H., and Kanehisa, M. (1999). KEGG: Kyoto encyclopedia of genes and genomes. Nucleic Acids Res. 27, 29-34.

Pan, F., Meng, Q., Wang, Q., Luo, S., Chen, B., Khan, K. Y., et al. (2016). Endophytic bacterium Sphingomonas SaMR12 promotes cadmium accumulation by increasing glutathione biosynthesis in Sedum alfredii Hance. Chemosphere 154, 358-366. doi: 10.1016/j.chemosphere.2016.03.120

Patrizia, B., Letizia, Z., Angelo, D. P., Di, L. D., Valentina, C., Giuseppina, F., et al. (2015). Cadmium-inducible expression of the ABC-type transporter AtABCC3 increases phytochelatin-mediated cadmium tolerance in Arabidopsis. J. Exp. Bot. 66, 3815-3829. doi: 10.1093/jxb/erv185

Rajeev, M., Sushmitha, T. J., Aravindraja, C., Toleti, S. R., and Pandian, S. K. (2021). Exploring the impacts of heavy metals on spatial variations of sedimentassociated bacterial communities. Ecotoxicol. Environ. Saf. 209:111808. doi: 10.1016/j.ecoenv.2020.111808

Reynders, H., van der Ven, K., Moens, L. N., van Remortel, P., De Coen, W. M., and Blust, R. (2006). Patterns of gene expression in carp liver after exposure to a mixture of waterborne and dietary cadmium using a custom-made microarray. Aquat. Toxicol. 80, 180-193. doi: 10.1016/j.aquatox.2006.08.009

Robinson, M. D., McCarthy, D. J., and Smyth, G. K. (2010). edgeR: a bioconductor package for differential expression analysis of digital gene expression data. Bioinformatics 26, 139-140. doi: 10.1093/bioinformatics/btp616

Ruvindy, R., White, R. A. III, Neilan, B. A., and Burns, B. P. (2016). Unravelling core microbial metabolisms in the hypersaline microbial mats of shark Bay using high-throughput metagenomics. ISME J. 10, 183-196. doi: 10.1038/ismej. 2015.87

Sandaa, R.-A., Torsvik, V., and Enger, $\varnothing$ (2001). Influence of long-term heavymetal contamination on microbial communities in soil. Soil Biol. Biochem. 33, 287-295.

Sarria Carabalí, M. M., García-Oliva, F., Cortés Páez, L. E., and López-Lozano, N. E. (2020). Effect of cadmium contamination on the rhizosphere bacterial diversity of Echinocactus platyacanthus. Rhizosphere 13:100187.

Sarwar, N., Imran, M., Shaheen, M. R., Ishaque, W., Kamran, M. A., Matloob, A., et al. (2017). Phytoremediation strategies for soils contaminated with heavy metals: modifications and future perspectives. Chemosphere 171, 710-721. doi: 10.1016/j.chemosphere.2016.12.116

Sharma, P. (2021). Efficiency of bacteria and bacterial assisted phytoremediation of heavy metals: an update. Bioresour. Technol. 328:124835. doi: 10.1016/j. biortech.2021.124835

Song, W. Y., Yamaki, T., Yamaji, N., Ko, D., Jung, K. H., Fujii-Kashino, M., et al. (2014). A rice ABC transporter, OsABCC1, reduces arsenic accumulation in the grain. Proc. Natl. Acad. Sci. U.S.A. 111, 15699-15704. doi: 10.1073/pnas. 1414968111

Su, L., Xie, Y., He, Z., Zhang, J., Tang, Y., and Zhou, X. (2021). Network response of two cherry tomato (Lycopersicon esculentum) cultivars to cadmium stress as revealed by transcriptome analysis. Ecotoxicol. Environ. Saf. 222:112473. doi: 10.1016/j.ecoenv.2021.112473

Takahashi, R., Bashir, K., Ishimaru, Y., Nishizawa, N. K., and Nakanishi, H. (2012). The role of heavy-metal ATPases, HMAs, in zinc and cadmium transport in rice. Plant Signal. Behav. 7, 1605-1607. doi: 10.4161/psb.22454

Tan, M., Cheng, D., Yang, Y., Zhang, G., Qin, M., Chen, J., et al. (2017). Coexpression network analysis of the transcriptomes of rice roots exposed to various cadmium stresses reveals universal cadmium-responsive genes. BMC Plant Biol. 17:194. doi: 10.1186/s12870-017-1143-y

Valls, M., and de Lorenzo, V. (2002). Exploiting the genetic and biochemical capacities of bacteria for the remediation of heavy metal pollution. FEMS Microbiol. Rev. 26, 327-338. doi: 10.1111/j.1574-6976.2002.tb00618.x

Wang, L., Wang, L.-A., Zhan, X., Huang, Y., Wang, J., and Wang, X. (2020). Response mechanism of microbial community to the environmental stress caused by the different mercury concentration in soils. Ecotoxicol. Environ. Saf. 188:109906. doi: 10.1016/j.ecoenv.2019.109906

Wang, M., Wang, L., Shi, H., Liu, Y., and Chen, S. (2021). Soil bacteria, genes, and metabolites stimulated during sulfur cycling and cadmium mobilization under sodium sulfate stress. Environ. Res. 201:111599. doi: 10.1016/j.envres. 2021.111599 
Wang, Q., Ma, L., Zhou, Q., Chen, B., Zhang, X., Wu, Y., et al. (2019). Inoculation of plant growth promoting bacteria from hyperaccumulator facilitated non-host root development and provided promising agents for elevated phytoremediation efficiency. Chemosphere 234, 769-776. doi: 10.1016/ j.chemosphere.2019.06.132

Wengenmayer, H., Ebel, J., and Grisebach, H. (2010). Enzymic synthesis of lignin precursors. Purification and properties of a cinnamoyl-CoA: NADPH reductase from cell suspension cultures of soybean (Glycine max). FEBS J. 65, 529-536. doi: 10.1111/j.1432-1033.1976.tb10370.x

Wu, B., He, T. L., Wang, Z. R., Qiao, S. Y., Wang, Y., Xu, F., et al. (2020). Insight into the mechanisms of plant growth promoting strain SNB6 on enhancing the phytoextraction in cadmium contaminated soil. J. Hazard. Mater. 385:121587. doi: 10.1016/j.jhazmat.2019.121587

Wu, B., Hou, S., Peng, D., Wang, Y., Wang, C., Xu, F., et al. (2018). Response of soil micro-ecology to different levels of cadmium in alkaline soil. Ecotoxicol. Environ. Saf. 166, 116-122. doi: 10.1016/j.ecoenv.2018. 09.076

Wu, B., Wang, Z., Zhao, Y., Gu, Y., Wang, Y., Yu, J., et al. (2019). The performance of biochar-microbe multiple biochemical material on bioremediation and soil micro-ecology in the cadmium aged soil. Sci. Total Environ. 686, 719-728. doi: 10.1016/j.scitotenv.2019.06.041

Xiao, K., Li, Y., Sun, Y., Liu, R., Li, J., Zhao, Y., et al. (2017). Remediation performance and mechanism of heavy metals by a bottom up activation and extraction system using multiple biochemical materials. ACS Appl. Mater. Interfaces 9, 30448-30457. doi: 10.1021/acsami.7b09520

Xu, L., Wang, Y., Liu, W., Wang, J., Zhu, X., Zhang, K., et al. (2015). De novo sequencing of root transcriptome reveals complex cadmium-responsive regulatory networks in radish (Raphanus sativus L.). Plant Sci. 236, 313-323. doi: 10.1016/j.plantsci.2015.04.015

Yuan, S., Xi, Z., Jiang, Y., Wan, J., Wu, C., Zheng, Z., et al. (2007). Desorption of copper and cadmium from soils enhanced by organic acids. Chemosphere 68, 1289-1297. doi: 10.1016/j.chemosphere.2007.01.046

Zhang, J., Zhang, M., Song, H., Zhao, J., Shabala, S., Tian, S., et al. (2020). A novel plasma membrane-based NRAMP transporter contributes to Cd and $\mathrm{Zn}$ hyperaccumulation in Sedum alfredii Hance. Environ. Exp. Bot. 176:104121. doi: 10.1016/j.envexpbot.2020.104121

Zhang, X., Yu, J., Huang, Z., Li, H., Liu, X., Huang, J., et al. (2021). Enhanced Cd phytostabilization and rhizosphere bacterial diversity of Robinia pseudoacacia L. by endophyte Enterobacter sp. YG-14 combined with sludge biochar. Sci. Total Environ. 787:147660. doi: 10.1016/j.scitotenv.2021.14 7660

Zhang, Y., Zhang, Y., Akakuru, O. U., Xu, X., and Wu, A. (2021). Research progress and mechanism of nanomaterials-mediated in-situ remediation of cadmiumcontaminated soil: a critical review. J. Environ. Sci. 104, 351-364. doi: 10.1016/ j.jes.2020.12.021

Zhang, Y., Cong, J., Lu, H., Yang, C., Yang, Y., Zhou, J., et al. (2014). An integrated study to analyze soil microbial community structure and metabolic potential in two forest types. PLoS One 9:e93773. doi: 10.1371/journal.pone.0093773

Zhao, Q., Yue, S., Bilal, M., Hu, H., Wang, W., and Zhang, X. (2017). Comparative genomic analysis of 26 Sphingomonas and Sphingobium strains: dissemination of bioremediation capabilities, biodegradation potential and horizontal gene transfer. Sci. Total Environ. 609, 1238-1247. doi: 10.1016/j.scitotenv.2017.07. 249

Zhou, Q., Guo, J. J., He, C. T., Shen, C., Huang, Y. Y., Chen, J. X., et al. (2016). Comparative transcriptome analysis between low- and high-cadmiumaccumulating genotypes of Pakchoi (Brassica chinensis L.) in response to cadmium stress. Environ. Sci. Technol. 50, 6485-6494. doi: 10.1021/acs.est. 5 b06326

Zhou, Z., Chen, Z., Pan, H., Sun, B., Zeng, D., He, L., et al. (2018). Cadmium contamination in soils and crops in four mining areas, China. J. Geochem. Explor. 192, 72-84. doi: 10.3390/ijerph18052617

Conflict of Interest: The authors declare that the research was conducted in the absence of any commercial or financial relationships that could be construed as a potential conflict of interest.

Publisher's Note: All claims expressed in this article are solely those of the authors and do not necessarily represent those of their affiliated organizations, or those of the publisher, the editors and the reviewers. Any product that may be evaluated in this article, or claim that may be made by its manufacturer, is not guaranteed or endorsed by the publisher.

Copyright (C) $2022 \mathrm{Wu}, \mathrm{Li}$, Peng, Wang and Xu. This is an open-access article distributed under the terms of the Creative Commons Attribution License (CC BY). The use, distribution or reproduction in other forums is permitted, provided the original author(s) and the copyright owner(s) are credited and that the original publication in this journal is cited, in accordance with accepted academic practice. No use, distribution or reproduction is permitted which does not comply with these terms. 